\title{
Effect of emulsion formulation on characteristics of pea protein- stabilized oil-in-water emulsions
}

\author{
Aslı Can Karaça ${ }^{1 *}$ \\ ${ }^{1}$ Department of Food Engineering, Istanbul Technical University, 34469, Istanbul, Turkey \\ *cankaraca@itu.edu.tr \\ *Orcid No: 0000-0002-4137-0644
}

Received:14 June 2020

Accepted: 14 September 2020

DOI: 18466/cbayarfbe. 752703

\begin{abstract}
The goal of this study was to investigate the effect of emulsion formulation on characteristics of oil-in-water emulsions. Varying concentrations of biopolymers including maltodextrin, gum arabic and pea protein were used in the formulation of emulsions created according to an extreme vertices design. Mean droplet size of oil-in-water emulsions changed between $0.9-2.5 \mu \mathrm{m}$ and decreased with increasing pea protein concentration. Creaming stability ranged between $9-100 \%$ and increased as the concentration of pea protein increased. The results of this research suggest that pea protein can be utilized as an emulsifier for oil-inwater emulsions with low oil concentration as it has the ability to decrease the mean droplet size and increase creaming stability of the emulsions.
\end{abstract}

Keywords: Creaming stability, droplet size, emulsion, pea protein.

\section{Introduction}

Oil-in-water emulsions are defined as homogeneous dispersions of oil droplets in water stabilized by emulsifiers [1]. Stability of an emulsion is defined as the ability of an emulsion to conserve its characteristics such as size distribution, state of aggregation, or spatial arrangement of droplets over time and plays an important role on quality and shelf life of numerous food products [2]. The changes in emulsion characteristics result in an alteration in the distribution or organization of molecules or the nature of molecules [3]. The dominant physicochemical mechanisms which lead to destabilization of food emulsions include creaming, flocculation, coalescence, Ostwald ripening, and phase inversion [4]. Creaming takes place due to density difference between the two phases. Oil droplets move upward because they have a lower density than the aqueous phase. Homogenization technique, processing parameters, emulsion formulation, and storage conditions are the key factors in emulsion stability [3].

Amphiphilic nature of proteins allows them to be commonly used in emulsion systems $[5,6]$. Proteins have the ability to adsorb at oil-water interfaces and form films around newly formed oil droplets [2]. Emulsifying properties of proteins mainly depend on their structure and interfacial behaviour. There has been a recent trend not only in the academia but also in the food industry towards the use of plant-based ingredients in product formulations. In addition to soy, wheat and corn proteins, pea protein is one of the most commonly investigated plant-based protein for its physicochemical and functional properties such as solubility, water/oil holding, emulsification, foaming and gelling [7]. Emulsifying properties of pea protein have been in the scope of several recent studies. Lam et al. [8] investigated emulsifying properties of pea proteins obtained from various different cultivars. The authors reported that pea proteins showed high emulsion stability ( $96 \%)$ and no significant difference was observed among cultivars. Effects of homogenization method [9] and several treatments including $\mathrm{pH}[10,11]$, heat $[9,12,13]$ and high pressure [14] on emulsifying properties of pea protein were reported.

Maltodextrin and gum arabic are commonly used wall materials in encapsulation of food ingredients. Maltodextrin is produced by hydrolysis of starch and contains linear amylose and branched amylopectin degradation products [15]. It is mainly used as a drying aid in encapsulation and has many advantages including high solubility, neutral taste and low cost. However, maltodextrin has very poor emulsifying properties and therefore it is used in combination with other surfaceactive materials such as proteins and gum arabic [16]. Gum arabic is a natural hetero polysaccharide obtained 
from acacia trees and contains L-arabinose, L-rhamnose, and D-glucuronic acid and 1,3-linked $\beta$-Dgalactopyranosyl units. Due to its surface active properties, it is widely used as an emulsifier and stabilizer in food and pharmaceutical formulations [17]. Both gum arabic and pea protein are reported to have good emulsifying properties, however they show high viscosity at relatively low concentrations. Therefore, a mixture of maltodextrin, gum arabic and pea protein were used in the formulation of emulsions in this study. Maltodextrin was used as a bulking agent and texture modifier whereas gum arabic and pea protein were used as co-surfactants. The main goal of this research was to examine the effect of emulsion formulation on some characteristics of pea protein-stabilized oil-in-water emulsions and to investigate whether pea protein can be used as an effective emulsifier.

\section{Materials and Methods \\ 2.1. Materials}

Bioploymer materials used (maltodextrin, gum arabic, and pea protein with $83 \%$ protein content) were supplied from Tate \& Lyle PLC (London, UK), Alland \& Robert (Paris, France), and Roquette (Lestrem, France), respectively. Sunflower seed oil was purchased from a local supplier.

\subsection{Emulsions Preparation}

Varying amounts of biopolymer materials were dissolved in $52 \mathrm{~g}$ of distilled water based on the formulations presented in Table1. For preparation of emulsions, $8 \mathrm{~g}$ of sunflower seed oil was added to these solutions and the mixture was homogenized with T18 Ultra-Turrax (IKA®-Werke GmbH \& Co. KG, Staufen, Germany) homogenizer at $12,000 \mathrm{rpm}$ for $7 \mathrm{~min}$.

Table 1. Emulsion formulations created according to extreme vertices design.

\begin{tabular}{cccc}
\hline Run & $\begin{array}{c}\text { Maltodextrin } \\
(\mathbf{\%})\end{array}$ & $\begin{array}{c}\text { Gum arabic } \\
\mathbf{( \% )}\end{array}$ & $\begin{array}{c}\text { Pea protein } \\
\mathbf{( \% )}\end{array}$ \\
\hline 1 & 38.25 & 1.25 & 0.50 \\
2 & 35.00 & 5.00 & 0.00 \\
3 & 34.75 & 3.75 & 1.50 \\
4 & 40.00 & 0.00 & 0.00 \\
5 & 36.50 & 2.50 & 1.00 \\
6 & 37.25 & 1.25 & 1.50 \\
7 & 33.00 & 5.00 & 2.00 \\
8 & 38.00 & 0.00 & 2.00 \\
9 & 35.75 & 3.75 & 0.50 \\
\hline
\end{tabular}

\subsection{Droplet Size}

A laser diffraction particle size analyzer was employed to characterize the droplet size distribution of oil-in-water emulsions (Mastersizer 3000, Malvern Instruments Ltd., Worcestershire, U.K.) and reported as volume-surface mean diameters [18].

\subsection{Creaming Stability}

Creaming stability of emulsions were determined by monitoring the cream layer separation after $1 \mathrm{~h}$ of storage [19].

\subsection{Experimental Design}

An extreme vertices mixture design with 9 experiments (Table 1) was used to investigate the effect of emulsion formulation on characteristics of oil-in-water emulsions. Mixture design was used in the study for designing experimental settings since the main goal of the research was to investigate the effect of formulation which was a mixture of three ingredients (maltodextrin, gum arabic and pea protein). The ranges of concentrations were selected as: $33-40 \%$ for maltodextrin, $0-5 \%$ for gum arabic, and $0-2 \%$ for pea protein. Measurements were performed in triplicate and reported as the mean \pm one standard deviation. Minitab ${ }^{\circledR}$ software (Minitab, LLC, Pennsylvania, US) was used for designing experiments, analyzing data and creating contour plots.

\section{Results and Discussion \\ 3.1. Droplet Size}

Droplet size of oil-in-water emulsions play an important role on the physicochemical stability of emulsions and is affected by not only the formulation of the emulsion but also the processing parameters [20]. In the present study, all emulsions were prepared under the same homogenization conditions and constant oil content in order to investigate the effect of emulsion formulation on emulsion characteristics. Maltodextrin was used as a bulking agent and texture modifier whereas gum arabic and pea protein were used as co-surfactants in the oil-inwater emulsions.

The mean droplet size of oil-in-water emulsions changed between 0.9-2.5 $\mu \mathrm{m}$ under the experimental conditions used. Droplet size distributions were found to be bimodal as indicated in Figure 1. Concentration of maltodextrin, gum arabic, and pea protein were identified as the significant factors for predicting mean droplet size of oilin-water emulsions $(p<0.05$; Table 2$)$. This predictive model was able to explain $89 \%$ of the variability in the data.

Maltodextrin contains linear amylose and branched amylopectin degradation products and shows no surfaceactive properties. On the other hand, presence of maltodextrin in the emulsion formulation has been reported to result in both stabilization and destabilization of the emulsion based on the homogenization conditions, emulsion formulation, and maltodextrin type [15]. Gum arabic contains different units and shows good emulsifying properties due to the amphiphilic protein unit in its structure [21]. Similarly, pea protein shows good emulsifying properties due to its amphiphilic 
structure and ability to decrease the interfacial tension at the oil-water interphase.

Figure 2 shows the effect of emulsion formulation on mean droplet size of oil-in-water emulsions. The mixture contour plot indicated that mean droplet size decreased from $\sim 2 \mu \mathrm{m}$ to $\sim 1 \mu \mathrm{m}$ as the concentration of pea protein increased from 0 to $2 \%$.

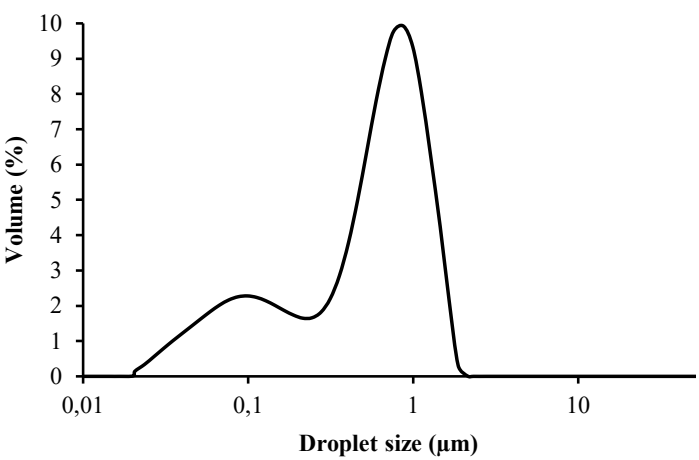

Figure 1. Droplet size distribution of oil-in-water emulsion \# Run 8.

It was observed that the emulsions containing $2 \%$ pea protein had the lowest droplet size. Peng et al [12] also reported that mean droplet size of pea protein-stabilized oil-in-water emulsions decreased (from $\sim 9.9$ to $\sim 1.3 \mu \mathrm{m}$ ) as the protein concentration increased from $0.1 \%$ to
$0.5 \%$. In another recent study by Aziz et al. [22], mean droplet size of oil-in water emulsions stabilized by acorn protein was reported to decrease as the protein concentration increased from $0.1 \%$ to $1 \%$.

An increase in protein concentration results in an effective reduction of interfacial tension, increased surface area and subsequent decrease in droplet size [23, 24]. It has been indicated that an optimum concentration of protein is required to sufficiently cover the newly formed oil droplets during homogenization and provide stability by preventing aggregation in emulsions stabilized by proteins.

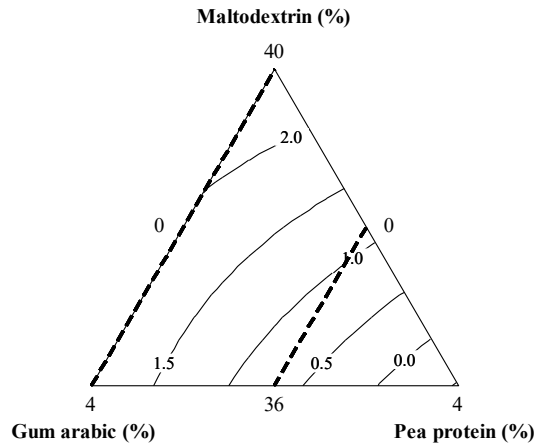

Figure 2. Mixture contour plot of mean droplet size of oil-in-water emulsions.

Table 2. Predictive models for mean droplet size and creaming stability of oil-in-water emulsions.

\begin{tabular}{lllll}
\hline Dependent variable & Independent variable & Coefficient & $\boldsymbol{p}$ value & Model fit \\
\hline Droplet size & Maltodextrin & 0.0612 & $p<0.05$ & $R^{2}=0.8939$ \\
& Gum arabic & 2.2352 & $p<0.05$ & $R^{2}$ (adj) $=0.7878$ \\
& Pea protein & -2.3987 & $p<0.05$ & $F=8.43$ \\
& Maltodextrin*Gum arabic & -0.0641 & $\mathrm{NS}$ & $p<0.05$ \\
& Maltodextrin*Pea protein & 0.0476 & $\mathrm{NS}$ & \\
Creaming stability & Maltodextrin & 0.2674 & $p<0.05$ & $R^{2}=0.9007$ \\
& Gum arabic & -207.282 & $p<0.05$ & $R^{2}($ adj) $=0.8013$ \\
& Pea protein & 261.079 & $p<0.05$ & $F=9.07$ \\
& Maltodextrin*Gum arabic & 5.9884 & $\mathrm{NS}$ & $p<0.05$ \\
& Maltodextrin*Pea protein & -5.8237 & $\mathrm{NS}$ & \\
\hline
\end{tabular}

\subsection{Creaming Stability}

Creaming is a common instability mechanism that occurs in emulsions which results in phase separation. Creaming stability of oil-in-water emulsions changed between $9 \%$ and $100 \%$. Concentration of biopolymer materials were identified as the significant factors for predicting creaming stability $(p<0.05$; Table 2$)$. This predictive model was able to explain $90 \%$ of data variation.

Mixture contour plot in Figure 3 presents the effect of emulsion formulation on creaming stability of oil-inwater emulsions. Creaming stability increased from $\sim 40 \%$ to $\sim 100 \%$ as the concentration of pea protein increased from 0 to $2 \%$. Emulsions produced with $2 \%$ pea protein showed the highest creaming stability. Increase in creaming stability with increased pea protein concentration was found to be in accordance with the results observed for mean droplet size. Ye [25] also reported increased creaming stability with increasing protein concentration up to $2 \%$. However, creaming stability was reported to decrease when the protein concentration was increased further. On the other hand, $\mathrm{Hu}$ et al [26] reported that optimum interfacial protein concentration and stability was achieved at 3\% protein 
concentration in soy protein-stabilized emulsions. Increased emulsion stability with increasing protein concentration observed at relatively low protein concentrations is attributed to increased concentration of interfacial adsorbed proteins, reduction of droplet size and increased viscosity which slow down phase separation $[13,23]$. Interfacial protein concentration and droplet size are indicated to be the main factors affecting emulsion stability [25].

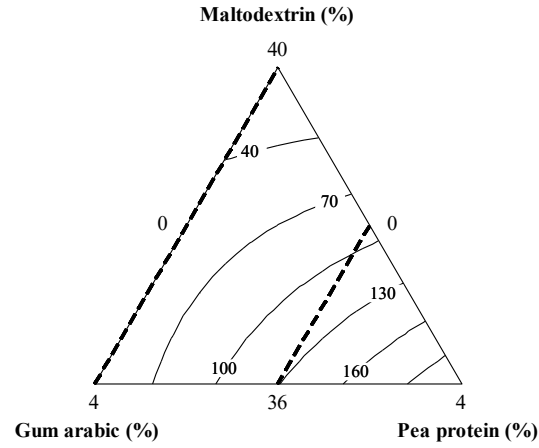

Figure 3. Mixture contour plot of creaming stability of oil-in-water emulsions.

\section{Conclusion}

Emulsion formulation had a significant effect on mean droplet size and creaming stability of oil-in-water emulsions stabilized by pea protein. Droplet size decreased and creaming stability increased with increasing pea protein concentration. The findings of this study indicate that pea protein can be utilized as an effective emulsifier for oil-in-water emulsions at low oil concentration. Further research is required to elucidate the effect of other formulation parameters such as oil concentration and type on characteristics of pea proteinstabilized oil-in-water emulsions.

\section{Acknowledgement}

The author would like to thank Aromsa A.S. for financial support of the study.

\section{Author's Contributions}

Aslı Can Karaça: Drafted and wrote the manuscript, performed the experiment and result analysis.

\section{Ethics}

There are no ethical issues after the publication of this manuscript.

\section{References}

1. Karayıldırım, ÇK. 2017. Characterization and in vitro evolution of antibacterial efficacy of novel hesperidin microemulsion. Celal Bayar University Journal of Science; 13: 943-947.

2. Dickinson, E. 2003. Hydrocolloids at interfaces and the influence on properties of dispersed systems. Food Hydrocolloids; 17: 2539.

3. McClements, DJ. Emulsion stability. In: Clydesdale FM (ed) Food emulsions: principles, practices, and techniques, 2nd edn. CRC Press, Boca Raton, 2005, pp 269-339.

4. McClements. DJ. 2007. Critical review of techniques and methodologies for characterization of emulsion stability. Critical Reviews in Food Science and Nutrition; 47: 611-649.

5. McClements, DJ. Emulsion ingredients. In: Clydesdale FM (ed) Food emulsions: principles, practices, and techniques, 2nd edn. CRC Press, Boca Raton, 2005, pp 95-174.

6. Coşkun, AEİ, Ocak, ÖÖ, Ocak, B, Ötleş, S. 2020. pH-dependent behavior and stability of protein-based particles in aqueous media. Celal Bayar University Journal of Science; 16: 95-102.

7. Wang, Y, Guldiken, B, Tulbek, M, House, JD, Nickerson, M. 2020. Impact of alcohol washing on the flavour profiles, functionality and protein quality of air classified pea protein enriched flour. Food Research International; 132: 109085.

8. Lam, ACY, Warkentin, TD, Tyler, RT, Nickerson, MT. 2017. Physicochemical and functional properties of protein isolates obtained from several pea cultivars. Cereal Chemistry; 94: 89-97.

9. Qamar, S, Bhandari, B, Prakash, S. 2019. Effect of different homogenisation methods and UHT processing on the stability of pea protein emulsion. Food Research International; 116: 13741385.

10. Gharsallaoui, A, Cases, E, Chambin, O, Saurel, R. 2009. Interfacial and emulsifying characteristics of acid-treated pea protein. Food Biophysics; 4: 273-280

11. Liang, HN, Tang, CH. 2013. pH-dependent emulsifying properties of pea [Pisum sativum (L.)] proteins. Food Hydrocolloids; 33: 309319.

12. Peng, W, Kong, X, Chen, Y, Zhang, C, Yang, Y, Hua, Y. 2016. Effects of heat treatment on the emulsifying properties of pea proteins. Food Hydrocolloids; 52: 301-310.

13. Chen, M, Lu, J, Liu, F, Nsor-Atindana, J, Xu, F, Goff, HD, Ma, J, Zhong, F. 2019. Study on the emulsifying stability and interfacial adsorption of pea proteins. Food Hydrocolloids; 88: 247-255.

14. Chao, D, Jung, S, Aluko, RE. 2018. Physicochemical and functional properties of high pressure-treated isolated pea protein. Innovative Food Science and Emerging Technologies; 45: 179185.

15. Dokic-Baucal L, Dokic P, Jakovljevic J. 2004. Influence of different maltodextrins on properties of $\mathrm{O} / \mathrm{W}$ emulsions. Food Hydrocolloids; 18: 233-239.

16. Reineccius GA. 2004. The spray drying of food flavors. Drying Technology; 22: 1289-1324.

17. Dave, NP, Gor, A. Natural polysaccharide-based hydrogels and nanomaterials: Recent trends and their applications. In Hussain $\mathrm{CM}$ (ed) Handbook of nanomaterials for industrial applications. Elsevier, Amsterdam, Netherlands, 2018, pp 36-66.

18. Can Karaca, A, Nickerson, MT, Low, NH. 2011. Lentil and chickpea protein-stabilized emulsions: Optimization of emulsion 
Celal Bayar University Journal of Science

Volume 16, Issue 3, 2020, p 257-261

formulation. Journal of Agricultural and Food Chemistry; 59: 13203-13211.

19. Stone, AK, Nickerson, MT. 2012. Formation and functionality of whey protein isolate - (Kappa-, iota-, and lambda-type) carrageenan electrostatic complexes. Food Hydrocolloids; 27: 271277.

20. Ozbek, ZA, Ergönül, PG. 2017. A review on encapsulation of oils Celal Bayar University Journal of Science; 13: 293-309.

21. Randall RC, Phillips GO and Williams PA. 1988. The role of the proteinaceous component on the emulsifying properties of gum arabic. Food Hydrocolloids; 2: 131-140.

22. Aziz, A, Khan, NM, Ali, F, Khan, ZU, Ahmad, S, Jan, AK Rehman, N, Muhammad, N. 2020. Effect of protein and oil volume concentrations on emulsifying properties of acorn protein isolate. Food Chemistry; 324: 126894.

23. Boostani, S, Hosseini, SMH, Golmakani, MT, Marefati, A, Hadi, NBA, Rayner, M. The influence of emulsion parameters on physical stability and rheological properties of Pickering emulsions stabilized by hordein nanoparticles. Food Hydrocolloids; 101 105520 .

24. Sun, LH, Lv, SW, Chen, CH, Wang, C. 2019. Preparation and characterization of rice bran protein-stabilized emulsion by using ultrasound homogenization. Cereal Chemistry; 96: 478-486.

25. Ye, A. 2008. Interfacial composition and stability of emulsions made with mixtures of commercial sodium caseinate and whey protein concentrate. Food Chemistry; 110: 946-952.

26. Hu, M, Xie, F, Zhang, S, Li, Y, Qi, B. 2020. Homogenization pressure and soybean protein concentration impact the stability of perilla oil nanoemulsions. Food Hydrocolloids; 101: 105575. 